\title{
In vitro MSC function is related to clinical reaction in vivo
}

\author{
Aileen L. Rowland ${ }^{1}$, Jiajie Jessica Xu1 ${ }^{1}$, Amanda Jo Joswig ${ }^{1}$, Carl A. Gregory ${ }^{2}$, Douglas F. Antczak ${ }^{3}$, \\ Kevin J. Cummings ${ }^{4}$ and Ashlee E. Watts ${ }^{1 *}$ (i)
}

\begin{abstract}
Background: We recently demonstrated that intracellular xenogen-contaminated autologous MSCS (FBS) and nonxenogen-contaminated allogeneic (ALLO) MSCs caused an adverse clinical response after repeated intra-articular injection in horses, whereas autologous (AUTO) MSCs did not. Our current objective was to use clinical data from the previous study to compare MSC stemness against adverse response indicated by synovial total nucleated cell count (TNCC) following intra-articular MSC injection.
\end{abstract}

Methods: Stemness, quantified by a trilineage differentiation (TLD) score; immunomodulation, quantified by mixed lymphocyte reactions (MLRs); and degree of $\mathrm{MHCl}$ expression, quantified by mean fluorescent intensity (MFI); were correlated to the synovial TNCC $24 \mathrm{~h}$ after naïve and primed injection.

Results: There was a trend of a negative correlation ( $p=0.21, r=-0.44)$ between TLD score and TNCC after primed injection in the ALLO group. Within the ALLO group only, there was a significant positive correlation $(p=0$. $05, r=0.77)$ between MHCI MFI and TNCC after naïve injection and a trend $(p=0.16, r=0.49)$ of a positive association of MHCI MFI to TNCC after primed injection. Within the FBS group only, there was a positive correlation ( $p=0.04, r=1)$ between TNCC and lymphocyte proliferation after both injections.

Conclusions: The trend of a negative correlation of TLD score and TNCC in the ALLO, but not the FBS group, together with the association of $\mathrm{MHCl}$ expression and TNCC in the ALLO group, indicates that improved stemness is associated with reduced MSC immunogenicity. When inflammation was incited by xenogen, there was a strong correlation of lymphocyte activation in vitro to adverse response in vivo, confirming that MLRs in vitro reflect MSC immunomodulatory activity in vivo. The relationship of stemness in vitro, suppression of lymphocyte activation in vitro, $\mathrm{MHCl}$ expression in vitro, and clinical response in vivo should be further investigated.

Keywords: MSC, Bone marrow, Horse, Joint, Intra-articular, Allogeneic, Immunogenicity, Trilineage differentiation, Stemness

\section{Background}

For decades, mesenchymal stem cells (MSCs) have been considered an immune-privileged cell that did not require donor-recipient matching prior to allo-transplantation. This was widely accepted due to the immunologic properties of MSCs in vitro: suppression of stimulated T cells, lack of MHCII expression, relatively low MHCI expression, and production of immunosuppressive cytokines [1].

\footnotetext{
*Correspondence: awatts@cvm.tamu.edu

'Department of Large Animal Clinical Sciences, Texas A\&M University, College Station, TX, USA

Full list of author information is available at the end of the article
}

In other words, MSCs have been understood to have both immunomodulatory properties that reduce inflammation and to lack immunogenic properties that influence allo-recognition. However, recent evidence in the mouse and horse has demonstrated induction of both cellular and humoral immune responses [2-5] and rejection of allo-transplanted MSCs from immune-competent recipients of MHC-mismatched allogeneic MSCs indicating allo-recognition [6].

In a large animal model, we recently demonstrated a local inflammatory response secondary to immune recognition of MSCs after repeated intra-articular 
injection of allogeneic but not autologous MSCs [7]. In that report, we also demonstrated an inflammatory response to autologous MSCs when MSCs had intracellular xenogen (fetal bovine serum; FBS) contamination. As expected, there was variability in the degree of local inflammation between horses after intra-articular injection within each group. Given the preponderance of data supporting the immunomodulatory function of MSC post-transplant, we suspected the variability of adverse response from each recipient was a result of variability of the immunomodulatory properties of donor MSCs. Specifically, that MSCs from some donors would reduce inflammation to a greater degree than MSCs from other donors. To assess for donor differences in immunomodulatory capacity, we used modified mixed lymphocyte reactions. But to assess for donor differences due to in vitro stemness, we needed an in vitro measure of MSC quality.

Many others have attempted to quantify stem cell quality to predict MSC efficacy and function using in vitro measurements such as motility, growth rate, and various measures of immunomodulatory function [811]. In vitro, the MSC is defined by its ability to undergo trilineage differentiation [12], and in vivo, MSCs are thought to remain quiescent in their stem cell niche while maintaining their differentiation potential $[13,14]$. Therefore, better maintenance of this inherent MSC characteristic (trilineage differentiation) of MSCs in vitro may reflect better MSC quality. Our objective was to determine if there was a relationship between MSC ability to undergo trilineage differentiation, MSC ability to suppress lymphocyte activation, or amount of MHCI expression in vitro and the in vivo adverse clinical reaction to MSCs from the horses in the aforementioned report.

\section{Methods}

Data and bone marrow-derived MSCs from a previous study that was approved by the university's Institutional Animal Care and Use Committee (IACUC \# 2013-097) were used [7]. For the study reported here, whole blood was collected from the same animals for DNA analysis and haplotype identification (IACUC \# 2015-0038). No animals were euthanized for the previous study or the study reported here.

\section{Study design}

Cytologic evaluations of synovial fluid and trilineage differentiation of MSCs from the abovementioned study were used. In that study, horses were assigned to one of three treatment groups: autologous MSCs depleted of FBS (AUTO, $n=6$ ), autologous MSCs not depleted of FBS (FBS, $n=6$ ), or allogeneic MSCs depleted of FBS (ALLO, $n=6$ ). In the allogeneic (ALLO) group, MSCs from one autologous (AUTO) horse were injected in an allogeneic recipient, for a total of six AUTO/ALLO pairs. The metacarpophalangeal joint was injected with approximately $10 \times 10^{6}$ MSCs, respective of the assigned treatment group on day 0 (naïve injection) and day 29 (primed injection). Synovial fluid samples from $24 \mathrm{~h}$ after the naïve and primed MSC injection were evaluated.

\section{Trilineage differentiation scoring}

A composite trilineage differentiation (TLD) score, a measure of stemness, was produced for all 12 donors (AUTO, $n=6$; FBS, $n=6$ ) from the average scores by a blinded individual for all lineages. Chondrogenesis was evaluated using the Bern Score based on the uniformity of stain uptake, cell density, and cell morphology with each category having a maximum of 3 , making 9 the total maximum chondrogenesis score (Table 1) [15]. The degree of osteogenesis was scored from 0 to 4 based on the percentage of cells with alizarin red $^{1}$ uptake in six randomized fields at a $\times 10$ objective on three replicate plates. Adipogenesis was also scored from 0 to 4 based on the percentage of cells with oil red $\mathrm{O}^{2}$ uptake; six randomized areas were scored in three replicate wells with the mean value being the adipogenesis score (Fig. 1). Each lineage was adjusted to a maximum score of 4 to weight each lineage equally, resulting in a total maximum total TLD score of 12. Mesenchymal stem cells were considered bipotent if TLD scores from one lineage were equal to or less than one.

\section{MHC haplotype analysis}

Haplotype analysis was performed on the recipients in the ALLO group, as well as donors from the AUTO group. Lymphocytes were isolated from the peripheral blood using a Ficoll ${ }^{3}$ gradient as previously described and DNA extracted using a commercially available kit ${ }^{4}$ [4]. Ten microsatellite loci, components of MHC I, II, or III, were analyzed to determine the haplotype of the individual. Briefly, this was done using the previously described method of amplifying genomic DNA using multiplex PCR with known primers of different loci and analyzing the size of the resulting products with commercially available software ${ }^{5}$ [16]. Haplotypes not previously established were reported as unknown, or as novel if two or more other individuals with the same haplotype had been identified.

\section{Population doubling time}

Cell counts and time in culture during expansion of MSCs for the previous study was used to compute population doubling time (PDT) from passages $2-3$ as a previously described measure of growth rate [17]. The following formula was used: PDT $=$ Time in culture $\times \log$ $2 /\left(\log _{f}-\log _{i}\right)$ where $f$ is final cell count and $i$ is the initial number of cell. 
Table 1 Trilineage differentiation scoring rubric for all lineages. Chondrogenesis rubric based on the Bern Score [15]

\begin{tabular}{|c|c|}
\hline Lineage & Score \\
\hline \multicolumn{2}{|l|}{ Chondrogenesis } \\
\hline \multicolumn{2}{|l|}{ Uniformity and darkness of stain } \\
\hline No stain & 0 \\
\hline Weak staining of poorly formed matrix & 1 \\
\hline Moderately even staining & 2 \\
\hline Even dark stain & 3 \\
\hline \multicolumn{2}{|l|}{ Distance between cells/amount of matrix accumulated } \\
\hline High cell densities with no matrix between & 0 \\
\hline High cell densities with a little matrix in between & 1 \\
\hline Moderate cell density with matrix & 2 \\
\hline Low cell density with a moderate distance between & 3 \\
\hline \multicolumn{2}{|l|}{ Cell morphologies represented } \\
\hline Condensed/necrotic/pycnotic bodies & 0 \\
\hline Spindle/fibrous & 1 \\
\hline $\begin{array}{l}\text { Mixed spindle/fibrous with rounded chondrogenic } \\
\text { morphology }\end{array}$ & 2 \\
\hline Majority rounded/chondrogenic & 3 \\
\hline \multicolumn{2}{|l|}{ Adipogenesis } \\
\hline $0 \%$ of cells with stain uptake & 0 \\
\hline $1-25 \%$ of cells with stain uptake & 1 \\
\hline $26-50 \%$ of cells with stain uptake & 2 \\
\hline $51-75 \%$ of cells with stain uptake & 3 \\
\hline $76-100 \%$ of cells with stain uptake & 4 \\
\hline \multicolumn{2}{|l|}{ Osteogenesis } \\
\hline $0 \%$ of cells with stain uptake & 0 \\
\hline $1-25 \%$ of cells with stain uptake & 1 \\
\hline $26-50 \%$ of cells with stain uptake & 2 \\
\hline $51-75 \%$ of cells with stain uptake & 3 \\
\hline $76-100 \%$ of cells with stain uptake & 4 \\
\hline
\end{tabular}

\section{$\mathrm{MHCl}$ expression}

Cryopreserved cells were thawed and CZ3.2 antibody ${ }^{6}$ was added undiluted to one million cells and incubated for $45 \mathrm{~min}$ at room temperature. Cells were then washed, and secondary antibody ${ }^{7}$ was added at a 1:100 dilution and incubated again for $45 \mathrm{~min}$, then washed twice and resuspended in DPBS before flow cytometry was performed. Unstained MSCs and unstained MSCs with only secondary antibody added were used as controls.

\section{Mixed lymphocyte reactions}

Cryopreserved cells were thawed and plated at a density of 50,000 cells per well $24 \mathrm{~h}$ prior to inactivation with mitomycin $C^{8}$ as previously described [18]. Responder and stimulator lymphocytes were isolated from two unrelated donors, respectively, using a Ficoll ${ }^{3}$ gradient with the addition of carbonyl iron ${ }^{9}$ [19]. Stimulator lymphocytes were also inactivated by incubation with $50 \mu \mathrm{g} / \mathrm{ml}$ mitomycin $\mathrm{C}$ for $30 \mathrm{~min}$ and then added at a density of $1 \times 10^{6}$ stimulator lymphocytes per well. Responder lymphocytes were stained with a commercially available nuclear stain, ${ }^{10}$ and $2 \times 10^{6}$ responder lymphocytes were added to each well. Cultures were maintained for 5 days in 1640 RPMI lymphocyte culture media. After 5 days, lymphocytes were collected and stained with anti-equine CD3+ antibody $^{11}$ at a 1:200 dilution. Flow cytometry was then performed on CD3+ T lymphocytes to assess proliferation with the use of the commercially available software. ${ }^{12}$ Stained, unstimulated responder lymphocytes were used as a negative proliferation control, and changes in mean fluoresce intensity were evaluated as a percent change from the negative control as previously described [20].

\section{Statistical analysis}

Spearman correlation coefficients were used to assess correlation in the AUTO, FBS, and ALLO groups of the TLD score to day 1 and day 30 TNCC. As a follow-up to immunogenicity versus immunomodulatory capacity of MSCs, the MFI of MHCI expression and the percent change of MFI of responder lymphocytes were compared to TNCC also using Spearman correlation coefficients. Stemness scores were also tested for a correlation using Spearman correlation coefficients to MFI of MHCI expression and PDT. Differences between the groups in TLD score, MFI of MHCI expression, and the percent change of MFI of responder lymphocytes were analyzed

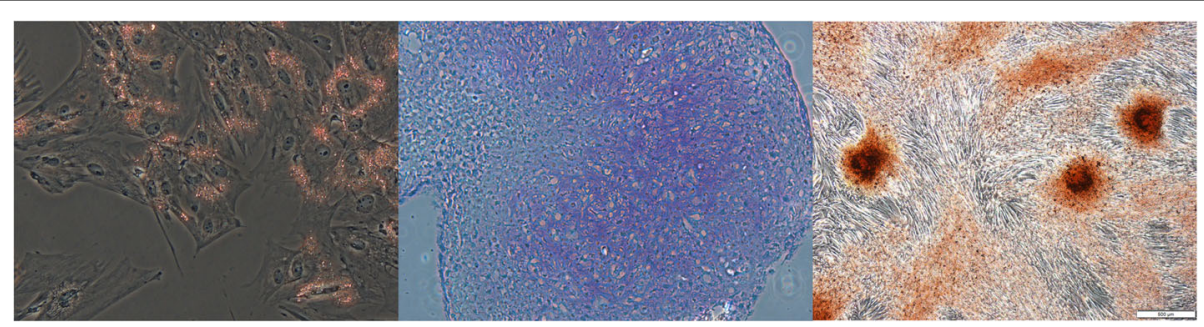

Fig. 1 Representative high scoring images for adipogenesis, chondrogenesis, and osteogenesis. All images were taken at $\times 10$ magnification 


\section{Composite Trilineage Differentiation Scores}

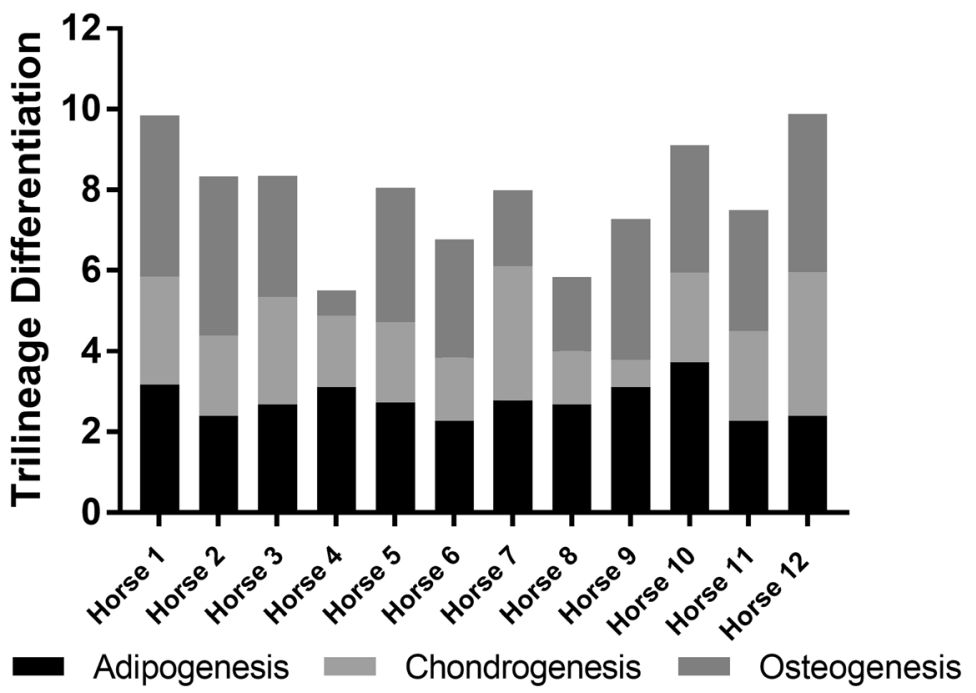

Fig. 2 Stacked trilineage differentiation (TLD) scores showing MSC differentiation from each donor in the AUTO and FBS groups. The black portion of the bar represents adipogenesis, light gray represents chondrogenesis, and dark gray represents osteogenesis. Each cell lineage was weighted equally with a maximum score of 4. Horses 1-6 (AUTO)received autologous cell depleted of FBS and were donors for horses in the ALLO group. Horses 7-12 (FBS) received autologous cells contaminated with intracellular xenogen. There were no significant differences between the groups

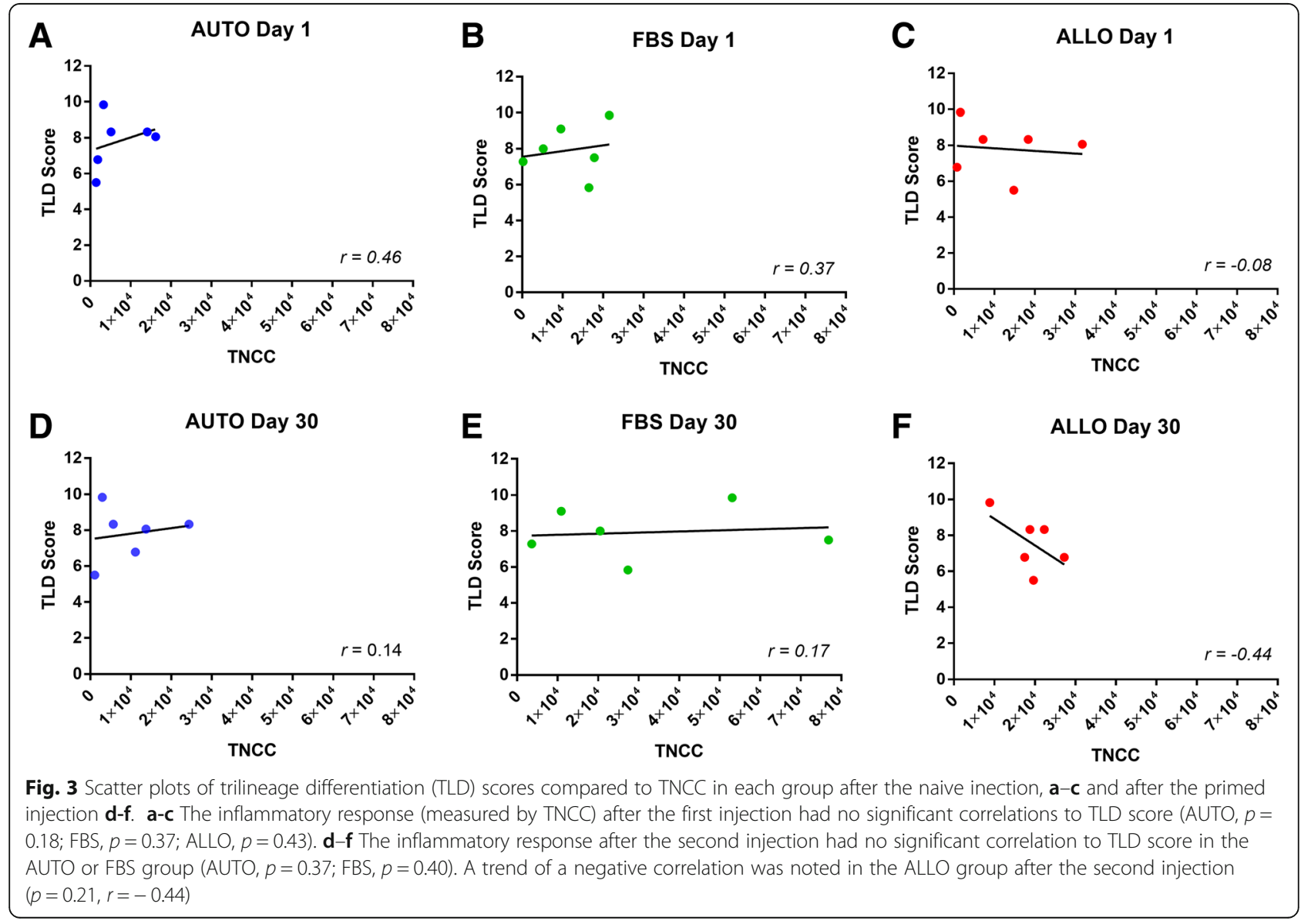


using a Wilcoxon rank sum test. A commercially available statistical software ${ }^{13}$ was utilized and differences considered significant when $p \leq 0.05$.

\section{Results}

Trilineage differentiation scores

TLD scores ranged from 5.5 to 9.7 out of 12 with a median score of 8 . There was no significant difference in the scores between the AUTO and FBS groups $(p=0.5)$ (Fig. 2). After the naïve intra-articular injection (day 1), there were no significant correlations between TLD and TNCC (AUTO, $p=0.18$; FBS, $p=0.25$; ALLO, $p=0.43$ ) (Fig. 3a-c). After the primed intra-articular injection (day $30)$, there were no significant correlations between TLD and TNCC in the AUTO or FBS group (AUTO, $p=0.37$; FBS, $p=0.40)$, but there was a trend $(p=0.21)$ of a negative correlation ( $r=-0.44$ in the ALLO group (Fig. 3d-f). Horse 4 (AUTO/ALLO group) and horse 9 (FBS group) were bipotent, receiving a TLD score of 1 for one lineage. Removal of horses 4 and 9 from the analysis did not change the direction or statistical significance of the result but did result in a more negative correlation in the ALLO group after second intra-articular injection (ALLO, $p=0.23, r=-0.53$; AUTO, $p=.21, r=-0.46$; FBS, $p=0.39, r=-0.2$ ).

\section{MHC haplotype analysis}

All MSC donors were MHC mismatches to their recipient (Table 2). Three horses in the ALLO group received cells from an individual that was a complete mismatch (both alleles were different), and three horses received cells from an individual that was a partial mismatch (one allele was similar, one was different). There was no significant difference in TNCC post-injection by Wilcoxon rank

Table 2 Mean fluorescence intensity and percentage of cells positive for $\mathrm{MHCl}$. Horses 1-6 comprised the AUTO group and were donors for single recipients in the ALLO group; horses 7-12 were in the FBS group

\begin{tabular}{lll}
\hline & Mean fluorescence intensity & Percentage of positive cells \\
\hline Horse 1 & 23.5 & 91.1 \\
Horse 2 & 88.2 & 99.9 \\
Horse 3 & 129 & 100 \\
Horse 4 & 426 & 100 \\
Horse 5 & 188 & 99.8 \\
Horse 6 & 68.5 & 100 \\
Horse 7 & 43.7 & 97.9 \\
Horse 8 & 79.9 & 99.7 \\
Horse 9 & 101 & 99.9 \\
Horse 10 & 85.1 & 99.9 \\
Horse 11 & 211 & 100 \\
Horse 12 & 93.1 & 99.9 \\
\hline
\end{tabular}

sum between the horses that were partial mismatches versus total mismatches.

\section{Population doubling time}

Population doubling time was not different between the groups (AUTO, median 3.1 days; FBS, median 1.7 days). There was no correlation between PDT and TLD score in either group.

\section{$\mathrm{MHCl}$ expression}

MSCs from all donors in the AUTO and FBS groups were positive for MHCI expression (percentage of cells expressing MHCI median, 99.9\%; range, 91.1-100\%) (Fig. 4). Mean fluorescent intensity (MFI) ranged widely between individuals (median, 88.2; range, 23.5-426) (Table 3). There was no correlation between MHCI MFI and TLD $(r=-0.26)$. There was no correlation between MHCI MFI and TNCC in the AUTO or FBS group at either time point. In the ALLO group, there was a significant positive correlation $(p=0.05, \quad r=0.77)$ between MHCI MFI and TNCC at day 1 as well as a positive trend at day $30(p=0.16, r=0.49)$.

\section{Mixed lymphocyte reactions}

MSCs from two horses in the FBS group were unavailable to complete mixed lymphocyte reactions. There was no significant correlation between TLD score and percent change in mean fluorescence intensity (MFI) of responder lymphocytes in either group (AUTO and FBS) or

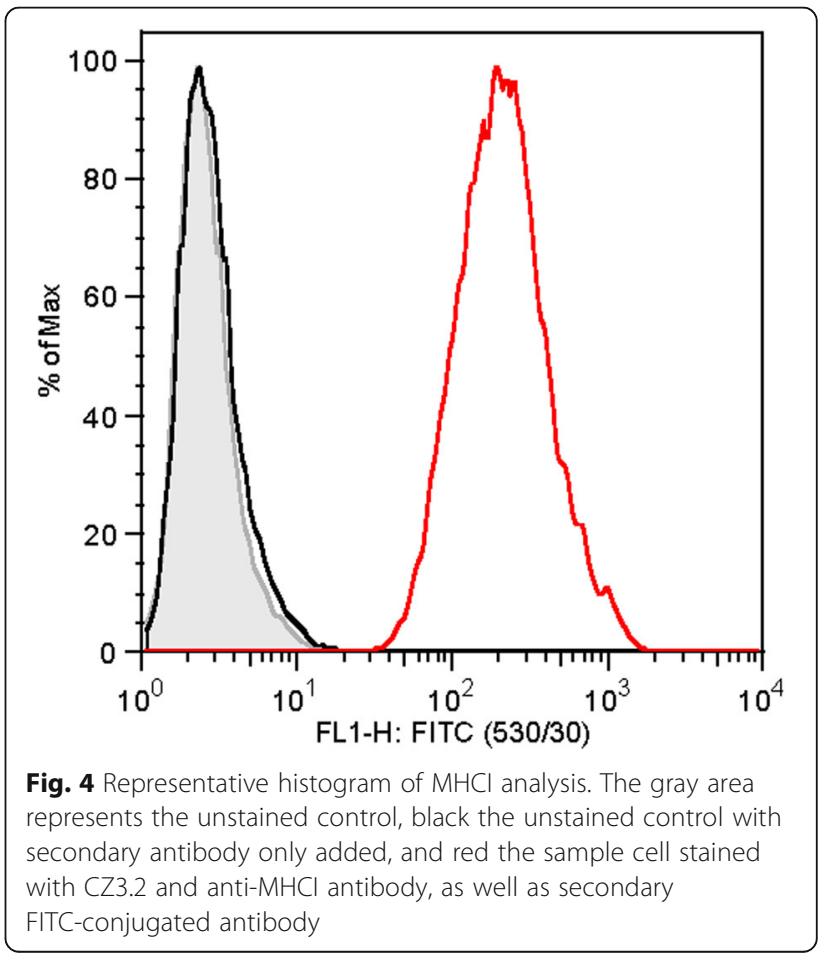


Table 3 Haplotype analysis of horses 1-6 and 13-18. Horses 1-6 comprised the AUTO group and were donors for the ALLO group; horses 13-18 were the ALLO group and recipients of MSCs from horses in the AUTO group. There were no complete matches between donor and recipient

\begin{tabular}{|c|c|c|c|c|c|c|c|c|c|c|c|}
\hline MHC class & 1 & I & III & III & $\|$ & ॥ & $\|$ & $\|$ & ॥ & $\|$ & \\
\hline \multirow[t]{2}{*}{ Microsatellite loci } & UMNJH-38 & COR110 & ABGe9019 & UMNe65 & ABGe9030 & EQMHC1 & COR112 & COR113 & UM011 & COR114 & \\
\hline & & & & & & & & & & & Haplotype \\
\hline \multicolumn{12}{|c|}{ AUTO group (donors) } \\
\hline \multirow[t]{2}{*}{ Horse 1} & 165 & 219 & 316 & 257 & 206 & 192 & 256 & 270 & 174 & 234 & Nov_07 \\
\hline & 156 & 211 & 318 & 263 & 215 & 194 & 256 & 270 & 178 & 245 & Nov_05 \\
\hline \multirow[t]{2}{*}{ Horse 2} & 156 & 221 & 299 & 257 & 212 & 190 & 254 & 260 & 172 & 243 & A5a \\
\hline & 156 & 211 & 299 & 257 & 205 & 192 & 260 & 268 & 172 & 251 & Nov_03 \\
\hline \multirow[t]{2}{*}{ Horse 3} & 165 & 211 & 314 & 259 & 206 & 190 & 264 & 268 & 169 & 259 & Nov_06 \\
\hline & 156 & 221 & 314 & 259 & 205 & 194 & 256 & 270 & 172 & 249 & QHnov04 \\
\hline \multirow[t]{2}{*}{ Horse 4} & $* *$ & 221 & 312 & 261 & 207 & 190 & 237 & 264 & 180 & 243 & A10a \\
\hline & $* *$ & 211 & 314 & 259 & 206 & 190 & 264 & 268 & 169 & 259 & Unknown \\
\hline \multirow[t]{2}{*}{ Horse 5} & 156 & 221 & 314 & 259 & 205 & 194 & 256 & 270 & 172 & 249 & QHnov04 \\
\hline & 156 & 211 & 318 & 257 & 212 & 190 & 262 & 270 & 184 & 245 & A19 \\
\hline \multirow[t]{2}{*}{ Horse 6} & 156 & 209 & 297 & 269 & 205 & 194 & 258 & 260 & 169 & 243 & Nov_02 \\
\hline & 156 & 221 & 314 & 259 & 205 & 194 & 256 & 270 & 172 & 249 & QHnov04 \\
\hline \multicolumn{12}{|c|}{ ALLO group (recipients) } \\
\hline \multirow[t]{2}{*}{ Horse 13} & 156 & 221 & 299 & 257 & 212 & 190 & 254 & 260 & 172 & 243 & A5a \\
\hline & 156 & 221 & 314 & 259 & 205 & 194 & 256 & 270 & 172 & 249 & QHnov04 \\
\hline \multirow[t]{2}{*}{ Horse 14} & 156 & 221 & 299 & 257 & 212 & 190 & 254 & 260 & 172 & 243 & $\mathrm{~A} 5 \mathrm{a}$ \\
\hline & 156 & 211 & 301 & 263 & 211 & 184 & 252 & 260 & 169 & 243 & Nov_01 \\
\hline \multirow[t]{2}{*}{ Horse 15} & 156 & 221 & 299 & 257 & 212 & 190 & 256 & 260 & 172 & 243 & A5A \\
\hline & 156 & 211 & 318 & 257 & 215 & 194 & 256 & 270 & 178 & 245 & Nov_05 \\
\hline \multirow[t]{2}{*}{ Horse 16} & 156 & 209 & 297 & 269 & 205 & 194 & 258 & 260 & 169 & 243 & Nov_02 \\
\hline & 156 & 211 & 301 & 263 & 211 & 184 & 252 & 260 & 169 & 243 & Nov_01 \\
\hline \multirow[t]{2}{*}{ Horse 17} & 156 & 211 & 299 & 257 & 207 & 190 & 237 & 266 & 179 & 241 & $\mathrm{~A} 1$ \\
\hline & 156 & 221 & 314 & 259 & 205 & 194 & 256 & 270 & 172 & 249 & QHnov04 \\
\hline \multirow[t]{2}{*}{ Horse 18} & 156 & 221 & 299 & 257 & 212 & 190 & 254 & 260 & 172 & 243 & A5a \\
\hline & 156 & 221 & 299 & 257 & 212 & 190 & 254 & 260 & 172 & 243 & A5a \\
\hline
\end{tabular}

Asterisks indicate when microsatellite loci could not be determined

overall. There was no significant correlation between TNCC and percent change in MFI in the AUTO or ALLO group after first or second injection (Fig. 5). There was a significant correlation between TNCC and percent change in mean fluorescence intensity (MFI) in the FBS group after both first and second injection (day 1 , $p=0.04, r=1$; day $30, p=0.04, r=1$ ) (Fig. 5)

\section{Discussion}

We previously demonstrated that repeated intra-articular injection of intracellular xenogen-contaminated autologous MSCs and allogeneic MSCs without intracellular xenogen resulted in an adverse clinical response after the second intra-articular injection in horses [7]. In that report, there was a significant intra-articular inflammation following the second injection because of immune recognition of foreign antigens: either allogen or xenogen.

Our objective for the study reported here was to use data and MSCs from that study to ascertain the relationship between stemness, immunomodulatory properties and recipient response. We expected that we would find a significant negative correlation of TLD score to TNCC, our measure of intra-articular inflammation, in both inflamed groups because of enhanced immunomodulatory properties of more plastic MSCs. However, we found a trend of a correlation only in the allogeneic group. The trend of a negative correlation in the ALLO group suggested reduced MSC immunogenicity with improved MSC stemness. To further investigate this trend, we evaluated the degree of MHCI expression on all MSCs 


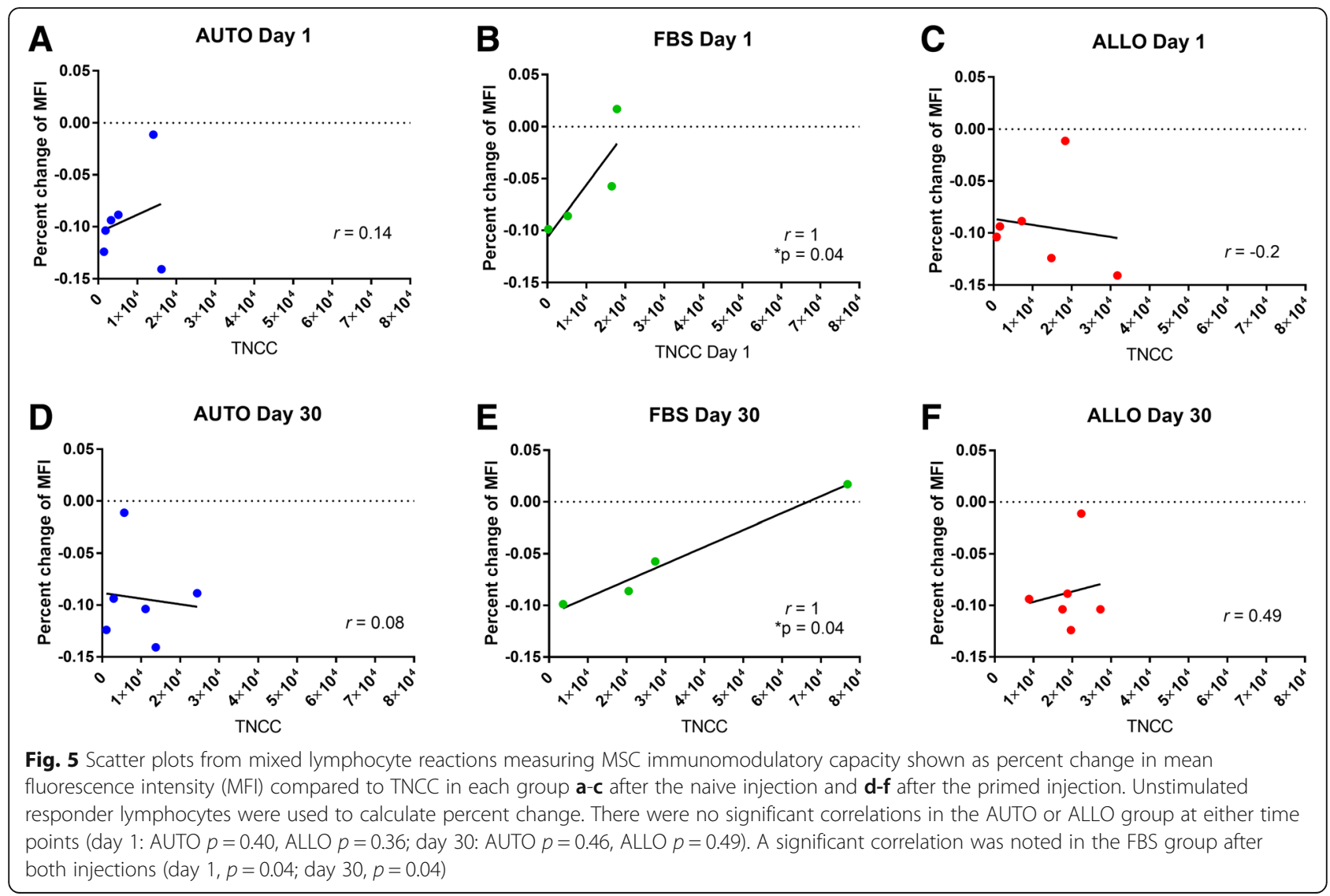

(AUTO and FBS). We found a negative correlation of MHCI expression to TNCC in the ALLO group and no relationship with TLD scores in any group. It has been suggested by others that MSCs with a greater degree of stemness express less MHCI [21], and our data supports that MHCI expression on allogeneic MSCs impacts adverse recipient response [22].

The degree of MHCI expression is an important MSC characteristic [23]. Adult-derived MSCs are known to have reduced MHCI expression compared to other somatic cells, and this MSC characteristic has contributed to the immune-privileged label that MSCs are often given [24]. Although low, the expression of MHCI was ubiquitously positive from MSCs in both groups. This is not surprising, as some MHCI expression is required because lack of MHCI will lead to recognition and destruction of any cell within the host by natural killer cells [25]. The importance of the degree of MHCI expression has been recognized and investigated. Berglund et al. utilized TGF- $\beta 2$ to reduce MHCI expression in an effort to minimize allo-recognition of MSCs [26]. Our work testing the recipient response to MHC mismatched MSC injections supports this notion that a reduction in MHCI expression by MSCs may reduce allo-recognition, and degree of MHCI expression by MSCs may be an important measure of MSC quality. While we understand that
MHC-mismatched allogeneic MSCs elicit an inflammatory reaction, the immune distance between haplotypes is unknown at this time, making the degree of mismatch between different haplotypes difficult to interpret (Table 3).

Interestingly, when evaluating mixed lymphocyte reactions (MLRs), we found no relationship of stemness to immunomodulatory function. However, we did find a significant correlation between in vitro MLRs and in vivo TNCC in the FBS group after both the first and second injections. This confirms the validity of MLRs in predicting MSC function in the inflamed environment in vivo; when there is a significant inflammation, which in our case was induced by introduction of intracellular xenogen within MSCs, the immunomodulatory capacity of the MSC in vitro is related to its immunomodulatory capacity in vivo.

We chose TLD to quantify MSC quality as it is a basic defining characteristic of an MSC and is easily quantified. Others have used trilineage differentiation ability as a measure of MSC quality and found that it may predict efficacy [10]. We expected that our TLD scores might be a good measure of MSC quality to predict their immune-modulating properties in vivo. Instead, we found that trilineage differentiation ability was related to MSC immunogenicity but not immunomodulatory properties. 
One limitation of using a TLD score is that bipotent MSCs receiving a high score for two of the three tissue types could receive a higher score than tripotent MSCs with moderate scores for all three lineages. Horse 4 and horse 9 received a score of less than or equal to 1 in a single lineage, suggesting a bipotent instead of tripotent differentiation capability. Because we sought to evaluate stemness, thus the ability to differentiate equally into all three lineages, we removed the associated bipotent scores from the analyses, which did not change the results. In future studies using a TLD score, it will be important to consider the effect of a strongly bipotent MSC. Another limitation of our TLD score was the small range covered by the TLD scores and the ordinal nature of the data. A validated assay of trilineage differentiation ability that produced continuous data should be developed.

\section{Conclusions}

It is becoming clear that MSCs are not as immune privileged as was once thought. An improved understanding of the factors that contribute to MSC immunogenicity is needed and may lead to ex vivo techniques to minimize immunogenicity and enhance the therapeutic efficacy of allogeneic MSCs. Overall, we demonstrated that in vitro stemness might be related to allo-MSC immunogenicity but not immunomodulatory function, in vivo. We confirmed that MLRs in vitro reflect MSC immunomodulatory function in vivo, when the inflammatory stimulus is intracellular xenogen. The relationship of in vitro stemness, in vitro suppression of lymphocyte activation, MHCI expression, and clinical reaction in vivo should be further investigated.

\section{Endnotes}

${ }^{1}$ Sigma Aldrich, St. Louis, MO

${ }^{2}$ Sigma Aldrich, St. Louis, MO

${ }^{3}$ Ficoll Paque, GE Healthcare, Aurora, $\mathrm{OH}$

${ }^{4}$ DNeasey, Qiagen, Germantown, MD

${ }^{5}$ Biosystems Peakscanner software v1.0, Applied Biosystems Foster City, California, USA

${ }^{6}$ Antczak Laboratory, Baker Institute, Ithaca, NY

${ }^{7}$ Fluorescein-AffiniPure Goat-Anti Mouse IgG, Jackson ImmunoResearch, West Grove, PA

${ }^{8}$ Sigma Aldrich, St. Louis, MO

${ }^{9}$ Sigma Aldrich, St. Louis, MO

${ }^{10}$ CellTrace $^{\text {it }}$ Violet, Thermo Fisher Scientific, Waltham, MA

${ }^{11}$ Clone UC F6G, University of California, Davis, CA

${ }^{12}$ FlowJo, FlowJo LLC, Ashland, OR

${ }^{13}$ Prism, GraphPad, La Jolla, CA

\section{Abbreviations}

ALLO: Allogeneic; AUTO: Autologous; FBS: Fetal bovine serum; MSCs: Mesenchymal stem cells; PDT: Population doubling time; TLD: Trilineage differentiation; TNCC: Total nucleated cell count
Funding

Funding was provided by the Link Endowment for Equine Research at Texas A\&M University and the Linda and Dennis H. Clark '68 Chair for Equine Studies at Texas A\&M University .

\section{Availability of data and materials}

All data generated or analyzed during this study are included in this published article.

\section{Authors' contributions}

ALR contributed to the study design, data acquisition, analysis and interpretation of data, and manuscript preparation. JJX and DFA contributed to the data acquisition, analysis and interpretation of data, and manuscript preparation. AJ, CAG, and AEW contributed to the study design, analysis and interpretation of data, and manuscript preparation. KJC contributed to the analysis and interpretation of data and manuscript preparation. All authors read and approved the final manuscript.

\section{Ethics approval}

This study was approved by the university's Institutional Animal Care and Use Committee (IACUC protocol number 2013-097 and 2015-0038). No animals were euthanized for this study.

Consent for publication

Not applicable

\section{Competing interests}

The authors declare that they have no competing interest.

\section{Publisher's Note}

Springer Nature remains neutral with regard to jurisdictional claims in published maps and institutional affiliations.

\section{Author details}

${ }^{1}$ Department of Large Animal Clinical Sciences, Texas A\&M University, College Station, TX, USA. ²Department of Molecular and Cellular Medicine, Institute for Regenerative Medicine, Texas A\&M Health Science Center, College Station, TX, USA. 'Department of Microbiology and Immunology, Cornell University, Ithaca, NY, USA. ${ }^{4}$ Department of Population Medicine and Diagnostic Sciences, Cornell University, Ithaca, NY, USA.

Received: 20 April 2018 Revised: 3 October 2018

Accepted: 7 October 2018 Published online: 08 November 2018

\section{References}

1. Ryan JM, Barry FP, Murphy JM, Mahon BP. Mesenchymal stem cells avoid allogeneic rejection. J Inflamm (Lond). 2005. https://doi.org/10.1186/14769255-2-8.

2. Badillo AT, Beggs K, Javazon EH, Tebbets JC, Flake AW. Murine bone marrow stromal progenitor cells elicit an in vivo cellular and humoral alloimmune response. Biol Blood Marrow Transplant. 2007. https://doi.org/ 10.1016/j.bbmt.2006.12.447.

3. Berglund AK, Schnabel LV. Allogeneic major histocompatibility complexmismatched equine bone marrow-derived mesenchymal stem cells are targeted for death by cytotoxic anti-major histocompatibility complex antibodies. Equine Vet J. 2017;49:539-44. https://doi.org/10.1111/evj.12647.

4. Pezzanite LM, Fortier LA, Antczak DF, Cassano JM, Brosnahan MM, Miller D, et al. Equine allogeneic bone marrow-derived mesenchymal stromal cells elicit antibody responses in vivo. Stem Cell Res Ther. 2015. https://doi.org/ 10.1186/s13287-015-0053-x [doi].

5. Nauta AJ, Westerhuis G, Kruisselbrink AB, Lurvink EGA, Willemze R, Fibbe WE. Donor-derived mesenchymal stem cells are immunogenic in an allogeneic host and stimulate donor graft rejection in a nonmyeloablative setting. Blood. 2006. https://doi.org/10.1182/blood-2005-11-011650.

6. Oliveira RL, Chagastelles PC, Sesterheim P, Pranke P. In vivo immunogenic response to allogeneic mesenchymal stem cells and the role of preactivated mesenchymal stem cells cotransplanted with allogeneic islets. Stem Cells Int. 2017. https://doi.org/10.1155/2017/9824698.

7. Joswig AJ, Mitchell A, Cummings KJ, Levine GJ, Gregory CA, Smith R, et al. Repeated intra-articular injection of allogeneic mesenchymal stem cells causes an adverse response compared to autologous cells in the equine 
model. Stem Cell Res Ther. 2017;8(8). https://doi.org/10.1186/s13287-0170503-8 [doi].

8. Lysák D, Koutová L, Holubová M, Vlas T, Miklíková M, Jindra P. The quality control of mesenchymal stromal cells by in vitro testing of their immunomodulatory effect on allogeneic lymphocytes. Folia Biol (Praha). 2016:62:120-130.

9. Bertolo A, Gemperli A, Gruber M, Gantenbein B, Baur M, Pötzel T, et al. In vitro cell motility as a potential mesenchymal stem cell marker for multipotency. 2015; doi:https://doi.org/10.5966/sctm.2014-0156.

10. Russell KC, Phinney DG, Lacey MR, Barrilleaux BL, Meyertholen KE, O'Connor KC. In vitro high-capacity assay to quantify the clonal heterogeneity in trilineage potential of mesenchymal stem cells reveals a complex hierarchy of lineage commitment. Stem Cells. 2010. https://doi.org/10.1002/stem.312.

11. Deskins DL, Bastakoty D, Saraswati S, Shinar A, Holt GE, Young PP. Human mesenchymal stromal cells: identifying assays to predict potency for therapeutic selection. Stem Cells Transl Med. 2013. https://doi.org/10.5966/ sctm.2012-0099.

12. Dominici M, Le Blanc K, Mueller I, Slaper-Cortenbach I, Marini F, Krause D, et al. Minimal criteria for defining multipotent mesenchymal stromal cells. The International Society for Cellular Therapy position statement. Cytotherapy. 2006. https://doi.org/10.1080/14653240600855905.

13. Okolicsanyi RK, Griffiths LR, Haupt LM. Mesenchymal stem cells, neural lineage potential, heparan sulfate proteoglycans and the matrix. Dev Biol. 2014. https://doi.org/10.1016/j.ydbio.2014.01.024.

14. Wong TY, Chang C, Yu C, Huang LLH. Hyaluronan keeps mesenchymal stem cells quiescent and maintains the differentiation potential over time. Aging Cell. 2017. https://doi.org/10.1111/acel.12567.

15. Grogan SP, Barbero A, Winkelmann V, Rieser F, Fitzsimmons JS, O'Driscoll S, et al. Visual histological grading system for the evaluation of in vitro-generated neocartilage. 2006; doi: https://doi.org/10.1089/ten. 2006.12.2141.

16. Tseng CT, Miller D, Cassano J, Bailey E, Antczak DF. Identification of equine major histocompatibility complex haplotypes using polymorphic microsatellites. Anim Genet. 2010. https://doi.org/10.1111/j.1365-2052. 2010.02125.x [doi].

17. Vidal MA, Kilroy GE, Johnson JR, Lopez MJ, Moore RM, Gimble JM. Cell growth characteristics and differentiation frequency of adherent equine bone marrow-derived mesenchymal stromal cells: adipogenic and osteogenic capacity. Vet Surg 2006; doi:VSU00197 [pii].

18. Paterson YZ, Rash N, Garvican ER, Paillot R, Guest DJ. Equine mesenchymal stromal cells and embryo-derived stem cells are immune privileged in vitro. Stem Cell Res Ther. 2014. https://doi.org/10.1186/scrt479.

19. Flaminio MJ, Rush BR, Davis EG, Hennessy K, Shuman W, Wilkerson MJ. Characterization of peripheral blood and pulmonary leukocyte function in healthy foals. Vet Immunol Immunopathol. 2000;73:267-285.

20. Schnabel LV, Pezzanite LM, Antczak DF, Felippe MJ, Fortier LA. Equine bone marrow-derived mesenchymal stromal cells are heterogeneous in MHC class II expression and capable of inciting an immune response in vitro. Stem Cell Res Ther. 2014. https://doi.org/10.1186/scrt402 [doi].

21. Pogozhykh O, Pogozhykh D, Neehus A, Hoffmann A, Blasczyk R, Müller T. Molecular and cellular characteristics of human and non-human primate multipotent stromal cells from the amnion and bone marrow during long term culture. Stem Cell Res Ther. 2015. https://doi.org/10. 1186/s13287-015-0146-6.

22. Berglund AK, Schnabel LV. Allogeneic major histocompatibility complexmismatched equine bone marrow-derived mesenchymal stem cells are targeted for death by cytotoxic anti-major histocompatibility complex antibodies. Equine Vet J. 2017. https://doi.org/10.1111/evj.12647.

23. Guest DJ, Ousey JC, Smith MR. Defining the expression of marker genes in equine mesenchymal stromal cells. Stem Cells Cloning. 2008;1:1-9.

24. Schu S, Nosov M, O'Flynn L, Shaw G, Treacy O, Barry F, et al. Immunogenicity of allogeneic mesenchymal stem cells. J Cell Mol Med. 2012. https://doi.org/10.1111/j.1582-4934.2011.01509.x.

25. Zajonc DM, Girardi E. Recognition of microbial glycolipids by natural killer T cells. Front Immunol. 2015. https://doi.org/10.3389/fimmu.2015.00400.

26. Berglund AK, Fisher MB, Cameron KA, Poole EJ, Schnabel LV. Transforming growth factor- $\beta 2$ downregulates major histocompatibility complex (MHC) I and MHC II surface expression on equine bone marrow-derived mesenchymal stem cells without altering other phenotypic cell surface markers. Front Vet Sci. 2017. https://doi.org/10.3389/fvets.2017.00084.

Ready to submit your research? Choose BMC and benefit from:

- fast, convenient online submission

- thorough peer review by experienced researchers in your field

- rapid publication on acceptance

- support for research data, including large and complex data types

- gold Open Access which fosters wider collaboration and increased citations

- maximum visibility for your research: over $100 \mathrm{M}$ website views per year

At $\mathrm{BMC}$, research is always in progress.

Learn more biomedcentral.com/submissions 